\title{
REMEMORAR PARA PRESERVAR: CONTAÇÃO DE HISTÓRIAS COMO INSTRUMENTO DA EDUCAÇÃO PATRIMONIAL
}

\author{
Remembering to preserve: storytelling as an instrument of heritage education
}

\author{
Rememorar para preservar: narración de histórias como instrumento de la educación \\ patrimonial
}

Ana Karoliny Teixeira da Costa*

Leoné Astride Barzotto**

\begin{abstract}
Resumo
Perceber o indivíduo a partir da interação que este estabelece com o seu meio é de grande importância para os rumos das novas propostas pedagógicas que se pretendem implantar no país. No entanto, isto gerou uma série de dúvidas sobre quais práticas pedagógicas utilizar para atender a esta necessidade de se incluir discussões de cunho sócio-históricas, de modo particularizado, na sala de aula - tendo em vista a diversidade cultural brasileira. A situação se torna ainda mais complexa quando se observa que, conforme hipótese levantada, há uma dissociação do ensino formal com a herança cultural do povo ao qual o ensino é direcionado. A partir disso, toma-se por objetivo refletir sobre a importância do Patrimônio Cultural nas relações de ensino-aprendizagem e enfocar o trabalho de rememoração, a partir de práticas de contação de histórias em sala de aula, como uma importante ferramenta a ser explorada no reconhecimento, na valorização e na preservação da cultura local. Para tanto, a metodologia adotada foi do tipo exploratória e descritiva. E se pôde constatar, entre outras questões, que a escola tem um importante papel na intermediação das políticas de preservação do Patrimônio Cultural junto aos indivíduos detentores das culturas a serem reconhecidas e preservadas.
\end{abstract}

PALAVRAS-CHAVE: Educação patrimonial. Rememoração. Contação de histórias.

\begin{abstract}
Perceiving the individual from the interaction that he establishes with his environment is of great importance for the directions of the new pedagogical proposals that are intended to be implemented in the country. However, this generated a series of doubts about which pedagogical practices to use to meet this need to include socio-historical discussions, in a particular way, in the classroom - taking into account the Brazilian cultural diversity. The situation becomes even more complex when one observes that, according to the hypothesis raised, there is a dissociation of formal education from the cultural heritage of the people to which the teaching is directed. From this, the objective is to reflect on the importance of Cultural Heritage in teaching-learning relations and to focus the work of remembrance, based on classroom storytelling practices, as an important tool to be explored in the appreciation and preservation of the local culture. For this purpose, the methodology was exploratory and descriptive. Among other issues, it was noted that the school has an important role in mediating the policies of preservation of the Cultural Patrimony with the individuals holding the cultures to be recognized and preserved.
\end{abstract}

\footnotetext{
* Mestre pelo Programa de Pós-Graduação em Letras, área de concentração: Literatura e Práticas Culturais (PPGL/FACALE/UFGD). Graduada em Letras/Literatura (FACALE/UFGD). Graduada em Pedagogia (UNINTER). Participa do Grupo de Pesquisa História da Educação, Memória e Sociedade (GEPHEMES), do Programa de Pós-Graduação em Educação, da UFGD. E-mail: autor@ hotmail.com

** Pós-Doutorado em Literatura com estágio na Universidade da Califórnia em Berkeley (CAPES 2015-2016). Professora Adjunta - Nível III - com dedicação exclusiva na Universidade Federal da Grande Dourados, MS. Professora permanente do Programa de Pós-Graduação em Letras (Mestrado) da UFGD; área de concentração: Literaturas e Práticas Culturais. Membro do GT da ANPOLL: Relações Literárias Interamericanas. E-mail: autor@ufgd.edu.br
} 
KEYWORDS: Patrimonial education. Rememoration. Storytelling.

\section{Resumen}

Percibir al individuo a partir de la interacción que éste establece con su medio es de gran importancia para los rumbos de las nuevas propuestas pedagógicas que se pretenden implantar en el país. Sin embargo, esto generó una serie de dudas sobre qué prácticas pedagógicas utilizar para atender a esta necesidad de incluir discusiones de cuño socio-históricas, de modo particularizado, en el aula - teniendo en vista la diversidad cultural brasileña. La situación se vuelve aún más compleja cuando se observa que, según hipótesis planteada, hay una disociación de la enseñanza formal con la herencia cultural del pueblo al que se dirige la enseñanza. A partir de eso, se toma por objetivo reflexionar sobre la importancia del Patrimonio Cultural en las relaciones de enseñanza-aprendizaje y enfocar el trabajo de rememoración, a partir de prácticas de conteo de historias en el aula, como una importante herramienta a ser explotada en el aula el reconocimiento, la valorización y la preservación de la cultura local. Para ello, la metodología adoptada fue del tipo exploratoria y descriptiva. Y se pudo constatar, entre otras cuestiones, que la escuela tiene un importante papel en la intermediación de las políticas de preservación del Patrimonio Cultural junto a los individuos poseedores de las culturas a ser reconocidas y preservadas.

PALABRAS CLAVE: Educación patrimonial. Rememoración. Cuenta de historias.

\section{INTRODUÇÃO}

Todo o processo de aprendizagem se dá a partir de experiências humanas, sejam elas provenientes de formas pedagógicas, socioculturais, cognitivas. O interessante é notar que, independente da forma, há sempre um contato, direto ou indireto, com outro indivíduo para que de fato se estabeleça a aprendizagem. Esta concepção nos remete aos estudos de Vigotski sobre aprendizado; o qual toma a noção de ser humano enquanto resultado de processos internos em construção vinculados a inserção do homem em um determinado ambiente sociocultural.

Este pensamento passou a ser difundido no Brasil por volta da década de 1980 e 1990, quando foram adotadas, paradoxalmente, em discussões e políticas educacionais, as ideias de Piaget sobre a Teoria Construtivista. As propostas desses dois autores convergem ao notar que tanto um quanto o outro partem da análise de mecanismos internos para explicar o aparecimento de inovações e mudanças no desenvolvimento do homem. Como também, em ambos os trabalhos há uma preocupação em pensar o homem na relação com o seu meio social. Contudo, neste ponto de análise há de se fazer uma ressalva que influirá na bifurcação dessas duas importantes pesquisas para a discussão das novas práticas pedagógicas, como bem define Silva (2004, p. 639): “A interação com outros indivíduos têm, para Vigotski, um outro caráter [...], [trata-se de] uma necessidade ontológica, ou seja, é por meio da relação do homem com outros, com a natureza e com a história dessas relações, que este se humaniza".

Embora o enfoque desses pesquisadores não tenha sido criar uma teoria da aprendizagem, mas se empenhar em descobertas sobre o desenvolvimento humano; para o campo educacional, essas discussões trouxeram grandes transformações, as quais influíram, entre outras coisas, nos papeis ocupados pelos agentes do processo de ensino-aprendizagem. Assim, o professor passou a ser um mediador, um facilitador e o aluno, um sujeito no ato de aprender.

Este novo olhar para o aluno influiu na necessidade de reconhecê-lo em sua integralidade, isto é, como um produto do seu meio social e não simplesmente como "tábula rasa". Neste contexto, pode-se dizer que havia uma preocupação em se repensar as matrizes curriculares a partir de duas perspectivas essenciais e indissociáveis: o ser humano e a sua cultura. Em termos práticos, isso significa dizer que pensar o ensino-aprendizagem a partir do reconhecimento da cultura de um povo é priorizar uma prática pedagógica menos mecânica, 
menos automática, em detrimento de uma abordagem que priorize as relações humanas, respeitando-se suas individualidades, sua história constitutiva.

Entretanto, embora se reconheça os esforços e os avanços conquistados na educação até os dias de hoje, com a finalidade de se aproximar de uma pedagogia menos mecânica e mais humanizada, por assim dizer; um dos grandes desafios do sistema educacional brasileiro, no entanto, é a dificuldade que se tem em conjugar o legado da história construída pelos diversos povos e os conteúdos aplicados nas diferentes disciplinas nas escolas. Isto nos leva a uma segunda constatação que é complementar à primeira: pode-se dizer que há, em certa medida, uma dissociação do ensino formal com a herança cultural do povo ao qual o ensino é direcionado.

Tais hipóteses se fundamentam em reflexões acerca de diálogos travados com professores de escolas públicas, voltadas para o Ensino Básico Regular, localizadas na cidade de Dourados-MS; durante a aplicação de oficinas em eventos acadêmicos e ao ministrar cursos de Formação Continuada aos professores da rede. Diálogos estes que denotaram a dificuldade enfrentada por eles quando o assunto era colocar em prática as propostas encaminhadas de Educação Patrimonial; como também, o tema tratado neste artigo se fundamenta em discussões que remontam ao contexto de formação da história da educação brasileira e os conflitos de interesses sociopolíticos de cada período; além disso, são reafirmadas a partir de medidas legais adotadas no campo educacional, com a finalidade de amenizar tal dissonância, a exemplo da inclusão de um volume para tratar de temas transversais no Plano Curricular Nacional para o ensino fundamental (PCN), em 1997.

O grande desafio que se coloca, no entanto, é transformar as informações do PCN, como de outros documentos - de cunhos generalizados -, em práticas particulares, de acordo com as peculiaridades de cada grupo social localizado nas diferentes regiões do Brasil. A tarefa se torna ainda mais complexa quando se observa a escassez de materiais de pesquisas (de livre acesso/circulação ao público em geral, no caso, aos professores da rede de ensino básico) que sirvam de apoio para a formação de um corpus teórico no desenvolvimento de uma educação patrimonial sobre a cultura sul-matogrossense.

Diante disso, o presente artigo tomou por objetivo refletir sobre a importância do patrimônio cultural nas relações de ensino-aprendizagem. Da mesma forma, buscou-se enfocar o trabalho de rememoração, a partir de práticas de contação de histórias em sala de aula, como um importante método a ser explorado no reconhecimento, na valorização e na preservação da cultura local.

A metodologia adotada neste trabalho foi exploratória e descritiva, com coletas de dados a partir de pesquisas bibliográficas e documentais, além de experiências adquiridas ao ministrar oficinas de Contação de Histórias, em Formação Continuada na região de Mato Grosso do Sul.

\section{Teorias pedagógicas no contexto educacional brasileiro}

Definir um momento preciso na história nacional em que as ideias pedagógicas Construtivistas, desenvolvidas por Piaget, passaram a incorporar práticas educativas não é tarefa fácil, uma vez que é possível encontrar episódios em diferentes períodos, os quais carregam traços característicos dessa prática. Porém, há de se ater que esses traços, em sua maioria, dizem respeito a apenas alguns dos núcleos específicos de determinados pesquisadores e, portanto, não se torna passível afirmar que se trata de uma adoção, propriamente dita, das ideias Construtivistas.

José Sérgio Fonseca de Carvalho (2001), professor em Filosofia da Educação da USP, defende que apenas a partir da década de 1970 é que surgiram, de modo mais efetivo, as primeiras influências do Construtivismo em propostas didáticas oficiais. Sendo um desses documentos mais expressivos, que denotam a influência das ideias piagetianas, a construção da 
Lei de Diretrizes e Bases (LDB), de número 5.692/71. Neste documento, inclusive, contempla o conceito de desenvolvimento biopsicossocial ${ }^{1}$, que é cunhado por Piaget em seus trabalhos de pesquisa. Outros documentos que acabam sofrendo influência do Construtivismo são os atuais Parâmetros Curriculares Nacionais para o Ensino Fundamental (PCN), de 1997.

Com efeito, embora na década de 1970 já se utilize o Construtivismo como base em importantes documentos do cenário educacional brasileiro, é a partir da década de 1980 que o Construtivismo passou a atuar como uma teoria hegemônica, de modo a ser utilizada para análise de problemas educacionais, como também, na solução desses problemas a partir da adoção de novas práticas pedagógicas.

Essa nova fase por qual passou a educação brasileira não pode ser desvinculada do seu contexto sociopolítico e econômico. Uma vez que esta nova configuração no cenário da educação é modelada pelas demandas do seu mercado econômico, político e social, como afirma Newton Duarte. Este enfatiza que o ato de "aprender a aprender" ${ }^{2}$ - um conceito da teoria Construtivista - parte do "princípio de que a educação deva preparar o indivíduo para ser capaz de adaptar-se constantemente a um meio ambiente dinâmico" (DUARTE, 2001, p. 92).

Esse ambiente dinâmico de que fala Duarte (2001) se refere ao período que vai da década de 1930 até 1980, quando o Brasil passa por uma fase chamada de "Desenvolvimentismo", na qual há uma forte efervescência no processo de crescimento da renda per capita nacional. Trata-se de um período no qual se fortalece a industrialização brasileira, a internacionalização da economia, a instalação de indústrias transnacionais, a procura por mão-de-obra barata e o incentivo ao consumismo. Nesse sentido, esta nova necessidade de mercado parece ter sido um potencial catalizador para que se almejassem produzir um determinado tipo de sujeito a fim de atender às novas demandas do mundo do trabalho. A teoria Construtivista aplicada às práticas educacionais, em afinidade com a ideologia neoliberal, pareceu ser o melhor caminho a se seguir para alcançar esse projeto.

Isso se deve, em especial, ao se levar em consideração uma das principais críticas atribuída ao trabalho de Piaget que é a neutralização do social. Isto porque, embora se considere em seus trabalhos o desenvolvimento do homem a partir da relação que este estabelece com o seu meio, as diferenças econômicas e culturais são naturalizadas, desvinculadas das relações de poder que as constituem. Dessa forma, para Piaget "[...] existe a natureza e, produto dela, uma obra admirável: o homem. O mundo objetivo é, para ele a realização de leis naturais, de modo que a própria criação humana se encontra a ela subjugada" (KLEIN, 2005, p.77). Ou ainda, as coisas são como são porque a natureza as fez como deveriam ser e não há nada que se possa fazer para mudar, pois se trata de uma lei natural.

De fato, é importante destacar a necessidade de se adaptar às demandas sociais. Isto é um quesito essencial, inclusive, para que se consiga desenvolver uma vida de forma satisfatória. Contudo, o cuidado que se deve ter é de não fazer desta adaptação uma armadilha potencialmente perigosa de alienação. Há de se ficar atento para o modo como se trabalha as propostas pedagógicas do método "aprender a aprender", de forma que este não se desvincule de propostas de transformação da realidade social concreta. É preciso colocar como prioridade um trabalho que traga como foco a formação de indivíduos autônomos e aptos a exercerem suas capacidades para além das demandas da realidade cotidiana. É preciso, nesses termos, o desenvolvimento de sujeitos conscientes e transformadores do seu espaço social.

\footnotetext{
${ }^{1} \mathrm{O}$ homem passa a ser estudado na teoria piagetiana a partir de três perspectivas: biológica, psicológica e social. Isto significa dizer que, se por um lado, o homem pode ser visto como um organismo detentor de características genéticas doadas, as quais se manifestam por meio de mecanismos ontogenéticos; por outro, ele é regido por um conjunto de condutas humanas que possuem aspectos mental e social. Cabendo, no entanto, ao aspecto biológico se sobrepor ao grau de importância aos demais, em suas análises.

${ }^{2}$ De forma simplificada, significa dizer que se trata da formação dos indivíduos dotados de boas capacidades adaptativas para satisfazer as necessidades de mercado.
} 
É neste ponto que as discussões de Vigotski parecem atender melhor a esta ânsia por formar cidadãos conscientes, propriamente ditos; e não simplesmente adaptáveis às necessidades socioeconômicas do seu período. Para este pesquisador, é a partir da consciência e do momento em que o indivíduo toma posse/interage com processos sócio-históricos que ele conseguirá adquirir informações, habilidades, atitudes, valores, entre outros. Dessa forma, é preciso que haja um contato com a realidade vigente, com o meio ambiente e com as outras pessoas. Vigotski enfatiza em suas discussões a importância de processos sócio-históricos atrelados à ideia de aprendizado. Sendo este aprendizado passível somente a partir da interdependência entre indivíduos. Isto é, uma interdependência daquele que aprende, daquele que ensina e da relação entre essas pessoas.

Mas, a grande pergunta que fica é: como introduzir discussões de cunho sóciohistóricas, de modo particularizado, em práticas pedagógicas?

Preocupados em buscar uma resposta acerca da importância deste assunto, ainda que regidos pelos ideais piagetianos, documentos oficiais, tais como os Parâmetros Curriculares Nacionais do Ensino Médio, publicado em 1997, trazem como proposta, em um volume à parte, a abordagem em sala de aula de seis temas transversais: ética, pluralidade cultural, meio ambiente, saúde, orientação sexual e temas locais. Esses temas versam sobre a necessidade de um ensino que traga à baila dos conteúdos curriculares, assuntos de cunho sociais; com vistas a despertar no aluno uma identidade social e individual mais críticas. Sendo um dos principais objetivos deste documento fazer com que o professor possibilite ao aluno "conhecer e valorizar a pluralidade do patrimônio sociocultural brasileiro" (SECRETARIA DE EDUCAÇÃO, 1997, p. 6).

O imenso desafio lançado ao professor, no entanto, é saber lidar com o fato de que esses temas são tratados de forma ampla, como bem se observa logo na introdução deste documento; uma vez que, como se procura justificar, trata-se de um material que visa dar suporte ao professor, ou ainda, trata-se de um texto que toma por função servir apenas de parâmetro para o desenvolvimento de diferentes planos de ensino, tendo em vista as particularidades de cada região do país.

Assim, a partir deste documento, compreende-se que cabe ao professor, no papel de pesquisador, entender de forma crítica quais são as peculiaridades do seu local de atuação e de que forma este local dialoga com o todo, em termos regional, nacional e mundial. Nessa perspectiva, o que se deixa entrever é que, a partir deste olhar para o local, tem-se condições de contribuir para a construção de identidades sociais dos indivíduos em formação; há um estímulo ao sentimento de pertença àquele(a) lugar/cultura; e, consequentemente, contribui-se para a preservação da história da cultura daquele povo.

Partindo desses pressupostos, compreende-se que o trabalho com rememoração se apresenta como um importante instrumento para a concretização desse projeto de formação de cidadãos conscientes, críticos e com poder de transformar sua realidade socioeconômica e política, como se procurará abordar mais adiante.

\section{O processo de rememoração e a importância de seus canais de comunicação}

Maurice Halbwachs (2006) entende que as memórias são construções dos grupos sociais, os quais são responsáveis por determinar o que deve ser memorável, bem como, definir os lugares onde essas memórias devem ser preservadas. Para esse teórico, as noções de memórias sociais e individuais convergem, isto porque as memórias individuais são possíveis somente na medida em que se concebe a noção de indivíduo como produto de um grupo, visto que o homem está em constante processo de interação com os demais membros e, assim, "nossas lembranças permanecem coletivas e nos são lembradas por outros, ainda que se trate 
de eventos em que somente nós estivemos envolvidos e objetos que somente nós vimos" (HALBWACHS, 2006, p. 30).

$\mathrm{O}$ ato de "Rememorar", por sua vez, pode ser entendido como a atividade de resgate dessa memória. Isto significa dizer, no entanto, que não se trata simplesmente de trazer para o presente uma lembrança do passado, mas se trata de um ato de selecionar os fatos, configurálos e confirmar o reconhecimento da importância dessa memória para o indivíduo e para o seu grupo.

Gagnebin (1994) compreende que o ato de rememorar pode ser visto como um instrumento de transformação do presente (Cf. GAGNEBIN, 1994, p. 55). A transformação de que fala Gagnebin pode ser percebido, nos termos em que procuramos explanar neste texto, como uma transformação da relação do indivíduo com o seu grupo e do grupo frente aos demais grupos, através de um processo de identificação cultural dos sujeitos. Isto se dá uma vez que a rememoração pode ser vista como um resgate e uma valorização da memória coletiva de um grupo, que, por sua vez, nada mais é do que o resgate da identidade de uma cultura a partir da reafirmação daquilo que a singulariza, expresso por meio de costumes, tradições, hábitos, saberes, crenças, culinária, cantos, danças, entre outros.

Nesse sentido, em contraposição à lembrança, a memória se apresenta como uma atividade dinâmica, conforme vemos em Astor Antônio Diehl (2002, p. 116). Para este, a memória "constitui-se de um saber, formando tradições, caminhos - como canais de comunicação entre dimensões temporais -, ao invés de rastros e restos como no caso da lembrança" (2002, p.116, grifo meu).

Pode-se dizer que esses "canais de comunicação" são de extrema importância para a sobrevivência de uma cultura. Pois, um grupo se forma, conforme Sartre (1997), a partir da reciprocidade entre indivíduos. Nesse sentido, há uma correspondência de interesses, expectativas, objetivos, perspectivas, que são responsáveis pela união desse grupo e formação da sua identidade. A partir do momento em que se perde a reciprocidade, perde-se o sentido de identidade coletiva. Assim, esses canais são responsáveis por reafirmar os motivos de esses indivíduos estarem reunidos em grupos, a partir da rememoração de seus saberes, tradições, crenças, costumes; da mesma forma, esses canais também são responsáveis por determinar o reconhecimento deste grupo perante aos demais.

Nos estudos de Myrian Santos (1993) sobre memória, o leitor se depara com uma abordagem sobre "o pesadelo da amnésia coletiva", na qual a autora destaca quais seriam as consequências de uma sociedade sem memória. Entre outros aspectos, Santos reflete que uma sociedade carente de experiências e de conhecimentos passados, tornar-se-ia incapaz de "sentir, julgar e defender seus direitos" (SANTOS, 1993, p. 71).

Por isso é que se expressa uma necessidade de preservar e valorizar o Patrimônio Histórico e Cultural dos diferentes grupos sociais. A formação desse Patrimônio simboliza a memória que foi valorizada e materializada pelos poderes constituídos ao longo do tempo. Poderes estes reconhecidos não somente na conjuntura política, mas nas relações que circundam os espaços sociopolíticos e econômicos.

\section{Educação patrimonial e a valorização do patrimônio cultural}

Ao recuperar a etimologia da palavra "patrimônio", tem-se sua origem do latim na palavra patrimôniu, que decomposta significa patri (pai) e monium (recebido). Dessa forma, este termo tem sua origem histórica ligada ao conceito de herança, a um bem que pertence ao paterno. Patrimônio, assim, referia-se a um bem considerado de tamanho valor, a ponto de servir de herança a alguém. Esta herança, por conseguinte, tinha em si um caráter memorial e identitário, o qual era transferido aos seus herdeiros, de forma a manter a representação do pater 
através daquilo que o caracterizava, mantendo-se assim um canal de comunicação entre esses indivíduos. E, dessa forma, justificar-se-ia a necessidade de preservação.

Essa mesma definição, do Patrimônio como um bem, será adotada para o termo Patrimônio Cultural ao longo da trajetória de constituição do seu conceito. Um exemplo claro disso é quando em 1937 o presidente Getúlio Vargas cria o Serviço do Patrimônio Histórico e Artístico Nacional (SPHAN) e oferece a seguinte definição ao termo, no decreto-lei $\mathrm{n}^{\mathbf{0}} 25$, de 30 de novembro de 1937: "[patrimônio é um] conjunto de bens móveis e imóveis de interesse público [...] [que possuam] excepcional valor arqueológico ou etnográfico, bibliográfico ou artístico".

Assim, ao se fazer uma breve retrospectiva, tem-se que o "bem" guardado durante o século XX, como herança cultural do povo brasileiro, foi apenas aquele que interessava aos detentores do poder socioeconômico e político da época: a elite brasileira. Conforme se pode observar nas palavras de Lemos (1981, p. 22):

\footnotetext{
Em geral guardamos os objetos e as construções ricas da classe poderosa. Guardaramse os artefatos de exceção e perderam-se para todo o sempre os bens culturais usuais e corriqueiros do povo. Esses bens diferenciados preservados sempre podem levar a uma visão distorcida da memória coletiva, pois justamente por serem excepcionais não têm representatividade.
}

Esta política de apagamento das diferenças em detrimento da preservação da cultura da elite brasileira ficou conhecida como "pedra e cal", a qual perdurou até a década de 1970. Sendo um divisor de águas desta ideologia a promulgação da Constituição Federal de 1988 (CF), na qual se previa o reconhecimento e valorização da diversidade cultural, como se pode notar no texto do artigo 216 desta Carta Constitucional:

\footnotetext{
Constituem patrimônio cultural brasileiro os bens de natureza material e imaterial, tomados individualmente ou em conjunto, portadores de referência à identidade, à ação, à memória dos diferentes grupos formadores da sociedade brasileira, nos quais se incluem: as formas de expressão; os modos de criar, fazer e viver; as criações científicas, artísticas e tecnológicas; as obras, objetos, documentos, edificações e demais espaços destinados às manifestações artístico-culturais; os conjuntos urbanos e sítios de valor histórico, paisagístico, artístico, arqueológico, paleontológico, ecológico e científico (BRASIL, 1988).
}

Assim, o texto da Constituição de 1988 sofreu profundas mudanças, as quais foram responsáveis pela ampliação do termo e inclusão de demais grupos considerados marginalizados. No entanto, a tarefa não foi concretizada em sua integralidade. Isto porque, conforme aponta Ribeiro (2005), o texto da Carta ainda carece de regulamentação para se que possa permitir "uma política pública de patrimônio que possibilite a gestão democrática" (RIBEIRO, 2005, p. 190). A análise que a estudiosa faz permite perceber que falta um maior esforço no sentido de se estabelecer pontes dialógicas entre os trabalhos de preservação e as comunidades detentoras desses patrimônios.

Uma forma de contribuir com aquilo que se denominou "ponte dialógica" é por meio da Educação Patrimonial. A partir dela, torna-se possível contribuir no sentido de estimular e ampliar a participação de grupos sociais na identificação, reconhecimento e preservação dos seus próprios patrimônios culturais.

As discussões de incentivo a uma Educação Patrimonial iniciaram, em termos conceituais e práticos, segundo Horta (1999), a partir de 1983, quando foi realizado o I Seminário de Educação Patrimonial, no Museu Imperial de Petrópolis - RJ. A importância dessas discussões para Horta vai além da ideia de uma meta a ser cumprida pela educação brasileira contemporânea e órgãos responsáveis pela preservação patrimonial, uma vez que esta 
prática acaba por se tornar um instrumento de "alfabetização cultural", como coloca Horta (1999, p. 6).

Em sala de aula, a Educação Patrimonial busca trazer, em seus fundamentos conceituais e práticos, orientações, a professores e profissionais responsáveis pela preservação da cultura, de como preservar bens culturais e do meio ambiente histórico. Trata-se de um esforço que exige de seus agentes "um processo permanente e sistemático de trabalho educacional" (HORTA, 1999, p.6), a partir da observação direta dos bens culturais. Isto é, Educação Patrimonial não se faz com uma exposição de um assunto, ou de imagens em um período de aula, mas a partir de constantes conversas, reflexões e contatos interacionais dos alunos com esses bens culturais herdados.

Esta interação do trabalho de preservação com o grupo social também se mostra importante uma vez que são estes que determinarão o que de fato deve ser preservado, a partir da ideia que se tem do que realmente guarda um efeito significativo dentro de um vasto repertório de elementos que compõem um Patrimônio Cultural, para que se consiga concretizar os esforços de garantir a compreensão da memória social do grupo (Cf. LEMOS, 1981, p. 29).

Um grande desafio que se lança à Educação Patrimonial, no entanto, é que, com a ampliação do termo e uma abertura do leque de possibilidades de preservação, há necessidade da formulação de novas políticas de como preservar. Isto implica em dizer que é preciso também a elaboração de estratégias de Educação Patrimonial.

A Nova Historiografia, responsável por trazer um “frescor" às discussões sobre inclusão da história e cultura daqueles que na Historiografia Tradicional foram deixados à margem, é uma importante aliada no expoente de elementos deste novo processo de reconstrução dos saberes históricos. Nessa perspectiva, alguns instrumentos de investigação e registro passaram a contribuir fortemente para que auxiliassem os grupos menores a descobrirem o seu próprio patrimônio, a partir de lembranças até então silenciadas e dos lugares onde vivem, os quais também são responsáveis por "contar" essa história.

Entre esses instrumentos utilizados está a História Oral, que surgiu como importante fonte documental. Segundo Alberti (2005, p. 18), a História Oral é um método de pesquisa que "privilegia a realização de entrevistas com pessoas que participaram de, ou testemunharam, acontecimentos, conjunturas, visões de mundo, como forma de se aproximar do objeto de estudo". Por ser uma narrativa oral esta é também uma narrativa de memória, a qual carrega em si narrativa de identidade.

A partir desse trabalho de resgate da memória de uma cultura, utilizando como instrumento a História Oral, torna-se possível conhecer detalhes e versões, ou ainda, pontos de vistas distintos das histórias que envolvem o cotidiano de uma determinada cultura e suas relações de poder, nas diferentes instâncias de relações (familiar, trabalho, política, escola, religião, etc.).

A incógnita que fica é: como utilizar este instrumento tão rico em sala de aula, com alunos do ensino básico? Como criar práticas pedagógicas que abranjam tamanha pluralidade e complexidade cultural?

As perguntas feitas acima não são fáceis de serem respondidas e, de antemão, cabe deixar claro que o objetivo deste texto não é oferecer uma resposta pronta, feito uma fórmula que se encaixe a todos os casos. Até mesmo porque, se assim o fizesse, estaríamos fadados ao fracasso, visto a complexidade e a maleabilidade do objeto de análise, que é a construção/valorização/preservação de um Patrimônio Histórico e Cultural de um povo.

Mas, uma alternativa bastante viável ao trabalho em sala de aula e que contribui para o desenvolvimento de uma Educação Patrimonial é a atividade de contação de histórias - como se procurará mostrar a seguir. 


\section{Contação de histórias: uma proposta pedagógica a ser explorada}

Como se sabe, a arte de narrar histórias é muito antiga. Trata-se de uma atividade praticada pelos homens antes mesmo do surgimento da escrita. Nas culturas primitivas, esta prática era de suma importância, pois determinava a sobrevivência de um grupo. Era por meio dessas atividades de contação que os mais velhos compartilhavam, por meio de conselhos, suas experiências de caças, de crenças, de costumes, de enfrentamentos de perigos, de saberes dos seus antepassados, de suas viagens a terras distantes, entre outros (Cf. BENJAMIN, 2012, p. 213-240).

Porém, hoje, com frequência, esses narradores buscam suas fontes de pesquisa em registros escritos - resultados de pesquisas historiográficas ou de textos autorais, ao contrário dos contadores tradicionais que repassavam aquilo que ouviam ou compartilhavam suas próprias vivências.

Nas escolas, o trabalho com a Contação de Histórias também deve partir da ideia de professores pesquisadores, empenhados na formação de jovens contadores; sendo estes atuantes, de modo consciente, na preservação e valorização do seu Patrimônio Cultural. Nesse sentido, uma forma de se iniciar este trabalho é por meio de práticas que visem dialogar com conhecimentos prévios do jovem contador, como nos fala Ricardo Azevedo (2004):

Ao entrar em contato com um conto maravilhoso, uma quadrinha ou um dito da sabedoria popular, o estudante talvez pense: "Peraí! Meus pais conhecem isso! Isso eu já ouvi! Isso faz sentido para mim!” A partir daí, é perfeitamente possível imaginar que tal aluno volte para casa, conte o conto que aprendeu na escola e, no dia seguinte, traga outros contados pelo pai ou por algum parente (AZEVEDO, 2004, p. 158).

Esta é uma forma de mostrar ao aluno que a sua família, seus amigos, seus vizinhos, sua comunidade também tem uma cultura. E esta cultura merece uma atenção especial. É a partir do momento em que se faz um trabalho de valorização das raízes desta comunidade, da sua religião, das suas manifestações culturais, das suas expressões artísticas, da sua composição étnica e racial, e ainda, uma abertura de espaço para a partilha de suas histórias individuais; é que se desenvolve uma base sobre a qual se estruturam os processos identitários (Cf. FARIA \& GARCIA, 2002, p. 126).

Para que este trabalho com a contação se desenvolva é preciso, primeiro, que haja uma identificação entre conto e contador. E isto só é possível a partir do momento em que o sujeito se identifica com aquele conhecimento adquirido, por isso a importância do professor mediar/orientar o aluno em suas buscas pela sua própria história constitutiva, enquanto sujeito imbuído de identidade. Assim, a atividade de formação de jovens contadores se alimenta dessa curiosidade por buscar sempre novas histórias; dessa identificação com as narrativas orais tradicionais, as quais, embora submergidas em águas desconhecidas da fantasia, do sobrenatural, carregam em si temas essencialmente pertencentes à natureza humana, os quais são compreendidos pelos alunos.

É preciso que o jovem contador tenha o seu próprio tempo de "mergulhar" na narrativa, para que dela se aproprie. Ou ainda: "É preciso ter tempo para sonhar os contos, isto é, ruminálos interiormente, mas também é preciso ter a oportunidade de praticá-los, senão podem ser esquecidos" (SIMONSEN, 1987, p. 29).

E este esquecimento de que fala Simonsen (1987) pode ser entendido como próprio do organismo humano, enquanto resultado da seleção de processos de armazenamento de experiências na memória de cada indivíduo. Mas também, conforme se procurou defender desde o início deste texto, pode-se fazer referência a um esquecimento de uma memória coletiva. Por isso é que se mostra tão necessário o trabalho com instrumentos de Contação de Histórias com jovens narradores, em sala de aula e o seu estímulo na preservação, na 
valorização e na divulgação dessas narrativas em seus ambientes sociais; de forma a contribuir para uma sociabilidade dos resultados coletados como Patrimônios Culturais.

\section{CONSIDERAÇÕES FINAIS}

Embora não se trate de um assunto novo, propriamente dito, o trabalho e a reflexão sobre o assunto Educação Patrimonial com jovens do ensino básico se faz necessário e atual. Visto que este é um canal viável de comunicação entre os detentores da cultura e aqueles que pretendem desenvolver trabalhos de preservação e valorização do Patrimônio Cultural de povos, até então, abastados da história oficial da cultural nacional.

Como visto, o trabalho de rememorar é de suma importância para a sobrevivência desses grupos marginalizados. No entanto, a nova configuração sociopolítica e econômica na qual estamos inseridos faz com que muitos traços característicos de determinadas comunidades, tais como os cantos, as danças, as crenças, as festividades, os saberes populares, sejam esquecidos, em nome de uma globalização das informações e identitárias. Como consequência disso, os jovens dessas culturas às margens, muitas vezes, não se atentam e, dessa forma, não sabem valorizar aquilo que é de peculiar do seu grupo.

O trabalho com a Educação Patrimonial, que utiliza como instrumento a Contação de Histórias, busca esta "apresentação", por assim dizer, da sua própria cultura ao jovem e, por conseguinte, visa estimular a valorização das tradições culturais desses grupos menores. A partir de técnicas e práticas atualizadas, o indivíduo em formação tem condições de resgatar o hábito de ouvir e narrar histórias, com o intuito de preservar, valorizar e desenvolver traços identitários comuns do seu grupo, de modo a contribuir para a sobrevivência da sua cultura.

Cabe às escolas, nesse sentido, assumir seu papel de também responsáveis pelo diálogo entre políticas de preservação do Patrimônio Cultural e indivíduos detentores das culturas a serem reconhecidas e preservadas. O trabalho, como visto, não se limita a elencar fatos e objetos a serem preservados, mas a desenvolver canais de comunicação entre pesquisadores e comunidade. Além da necessidade de desenvolver nesse grupo social um sentimento de pertença aos bens herdados, com vistas a contribuir na formação de novas possibilidades reflexivas e críticas para a estruturação e o desenvolvimento desta sociedade no presente.

\section{REFERÊNCIAS}

ALBERTI, Verena. Manual de História Oral. Rio de Janeiro: FGV, 2005. Disponível em: <http://books.google.com.br/>. Acesso em 08/03/2017.

AZEVEDO, Ricardo. Formas literárias populares e formação de leitores. In: BARBOSA, Márcia H. S.; RETTENMAIER, Miguel; RÖSING, Tânia M. K. (Org.). Leitura, identidade e patrimônio cultural. Passo Fundo: UPF, 2004.

BENJAMIN, Walter. O narrador: considerações sobre a obra de Nikolai Leskov. In: Magia e técnica, arte e política: ensaios sobre literatura e história da cultura. São Paulo: Brasiliense, 2012. p. 213-239.

BRASIL. Presidência da República. Constituição da República Federativa do Brasil 1988. Disponível 
<http://www.planalto.gov.br/ccivil_03/constituicao/constituicaocompilado.htm>. Acesso em $08 / 03 / 2017$.

BRASIL. Presidência da República. DECRETO-LEI No 25, DE 30 DE NOVEMBRO DE 1937. Disponível em: <http://www.planalto.gov.br/ccivil_03/decreto-lei/Del0025.htm>. Acesso em 07/03/2017.

BRASIL. Decreto-Lei $n^{\circ}$ 5.692, de 11 de Agosto de 1971. Fixa Diretrizes e Bases para o Ensino de $1^{\circ}$ e $2^{\circ}$ graus e dá outras providências. Coletânea da Legislação Estadual de Ensino, Curitiba, Secretaria Educacional do Estado do Paraná (SEEC) - Fundepar, p. 589.

CARVALHO, J. S. F. de. Construtivismo: uma pedagogia esquecida da escola. Porto Alegre: Artmed Editora, 2001.

DIEHL, Astor. Cultura Historiográfica: memória, identidade e representação. Bauru: EDUSC, 2002.

DUARTE, N. Vigotski e o "aprender a aprender: crítica às apropriações neoliberais e pósmodernas da teoria vigotskiana. Campinas: Autores Associados, 2001.

FARIA, Hamilton; GARCIA, Pedro. Arte e Identidade Cultural na Construção de um Mundo Solidário. In: __. O reencantamento do mundo: arte e identidade cultural na construção de um mundo solidário. São Paulo: Polis, 2002.

GAGNEBIN, J. M. História e narração em W. Benjamin. São Paulo: Perspectiva, 1994.

HALBWACHS, M. A memória coletiva. São Paulo: Centauro, 2006.

HORTA, Maria de Lourdes Parreiras. Guia Básico de Educação Patrimonial. Brasília: IPHAN/Museu Imperial, 1999.

KLEIN, L. Construtivismo piagetiano: considerações críticas a concepção de sujeito e objeto. In: DUARTE, N. (org.). Sobre o construtivismo. Campinas: Autores Associados, 2005, p.6386.

LEMOS, Carlos A. C. O que é patrimônio histórico. São Paulo: Editora Brasiliense S.A., 1981.

RIBEIRO, Sandra Bernardes. Memória, cidadania e gestão do patrimônio cultural. São Paulo: Annablume, 2005. 
SANTOS, Myrian dos. O pesadelo da amnésia coletiva: um estudo sobre os conceitos de memória, tradição e traços do passado. Revista Brasileira de Ciências Sociais. São Paulo, n. 23, 1993, p. 70-85.

SARTRE, Jean-Paul. $O$ ser e o nada: ensaio de ontologia fenomenológica. Trad. Paulo Perdigão. Petrópolis: Vozes, 1997.

Secretaria de Educação Fundamental. Parâmetros Curriculares Nacionais: introdução aos parâmetros curriculares nacionais (v. 1). Brasília: MEC/SEF, 1997.

Secretaria de Educação Fundamental. Parâmetros Curriculares Nacionais: apresentação dos temas transversais, ética (v. 8). Brasília: MEC/SEF, 1997.

SHEDLOCK, Marie. Da introdução de A arte de contar histórias. In: GIRARDELLO, Gilka. (Org.). Baús e chaves da narração de histórias. Florianópolis: SESC, 2004.

SILVA, Flávia Gonçalves da. Conceitos de Vigotski no Brasil: Produção divulgada nos cadernos de pesquisa. Cadernos de Pesquisa. v. 34, n. 123, p. 633-661, set./dez. 2004.

SILVEIRA, Éder da Silva. História Oral e Memória: a construção de um perfil de HistoriadorEtnográfico. Ciência e conhecimento - revista eletrônica da Ulbra São Jerônimo - vol. 1, 2007. Disponível em: <http://www.cienciaeconhecimento.com.br/>. Acesso em 08/03/2017.

SIMONSEN, Michele. O Conto Popular. São Paulo: Martins Fontes, 1987.

Recebido em:30/10/2017

Aceito em: 25/01/2018 